\title{
"SEDICIONES Y CONJURACIONES SON ESTRAGO Y POLILLA»: EL TESTIMONIO DE LOS OBISPOS EN LA GESTIÓN DE LA CRISIS CATALANA DE 1640
}

\author{
POR \\ DAVID GARCíA TRIGUEROS ${ }^{1}$ \\ Universidad de Granada
}

\begin{abstract}
RESUMEN
La crisis sociopolítica de Cataluña durante el reinado de Felipe IV no solo motivó la intervención directa de la Corona, sino también la gestión del levantamiento en armas por parte de la Iglesia. Los testimonios de tres obispos del Principado -Francisco Pérez Roy, Diego Serrano y José Laínez, preconizados en las sedes de Elna-Perpiñán y Solsona- contribuyen a conocer de un modo más detallado la realidad social de la Cataluña de mediados del siglo XVII, además de ofrecer una visión precisa de la complejidad del entramado de intereses políticos suscitados en este conflicto.
\end{abstract}

PALABRAS CLAVE: guerra de los Segadores; Iglesia y Estado; obispos.

\section{"SEDITIONS AND PLOTS ARE HAVOC AND GRUB»: TESTIMONY OF THE BISHOPS IN THE CATALAN CRISIS OF 1640}

\begin{abstract}
The sociopolitical crisis of Catalonia under the reign of Philip IV of Spain justified not only the directly intervention of Crown but also the management of armed uprising for a part of the Church. The testimonies of three bishops of the Principality -Francisco Pérez Roy, Diego Serrano y José Lainez, originating from the bishopric of Elna-Perpiñán and Solsona- provides us with a detailed testimony of not only the social reality of Catalonia in the middle of the Seventeenth century, also to offer us an accurate image of the complexity of the political framework ant the different interests that arose during this conflict.
\end{abstract}

KEY WORDS: Reaper's War; Church and State; bishops

Cómo CITAR ESTE ARTículo / CITATION: García Trigueros, David. 2020. "Sediciones y conjuraciones son estrago y polilla": el testimonio de los obispos en la gestión de la crisis catalana de 1640». Hispania Sacra LXXII, 146: 479-490. https://doi.org/10.3989/ hs.2020.035

Recibido/Received 07-01-2019

Aceptado/Accepted 23-07-2019

\section{INTRODUCCIÓN}

Por la actualidad de la cuestión social y política, la crisis suscitada en Cataluña en 1640 sigue siendo hoy objeto de interés entre los investigadores, quienes procuran seguir dilucidando cuantas cuestiones intervinieron en la conocida como Revolta del segadors, así como en lo que la historiografía contemporánea ha denominado «Guerra de Separación»

1 david.garcia.trigueros@gmail.com / ORCID iD: https://orcid.org/0000-0002-1912-1959
(1640-1659). ${ }^{2}$ Un conflicto armado que ha querido encuadrarse dentro de la Guerra de los Treinta Años por la implicación de Francia en el asunto, y que puso de manifiesto las extremas consecuencias de la funesta política de Felipe IV en materia económica y fiscal, agravada además por el contexto de carestía de la España de mediados del siglo XVII.

2 Torres 2014, 33-64. Fuentes de archivo utilizadas: $A C A=$ Archivo de la Corona de Aragón; AGS = Archivo General de Simancas; BNE = Biblioteca Nacional; ADS = Archivo Diocesano de Solsona. Asimismo, se ha recurrido a la versión impresa del volumen V (1623-1644) del Dietari de la Generalitat de Catalunya (en adelante DGC), publicado por la Generalitat de Catalunya en 1999. 
Sobre esta materia en cuestión existen dos obras que resultan, a pesar de su antigüedad, verdaderas obras de referencia. Se trata de los trabajos monográficos publicados en los años cincuenta y setenta por Sanabre y Elliot, respectivamente, y que permiten adentrarnos en las múltiples aristas que definieron el conflicto catalán de 1640 . No obstante, y gracias a los nuevos trabajos que han ido surgiendo, que abren y ahondan en algunas de las líneas de investigación, se ha permitido también conocer más de cerca cuál es el papel que en este conflicto desempeñaron algunos agentes sociales y actores políticos de su tiempo.

De igual manera, hasta ahora ha despertado poco interés el papel desempeñado por los prelados catalanes en este contexto. $Y$ es que el recorrido historiográfico de los obispos en el marco de la Guerra de Cataluña parece quedar limitado al papel subsidiario que estos ejercieron con respecto a la Corona, quedando sometidos a la voluntad real por medio del vínculo regalista que les había preconizado en sus respectivas sedes. Así pues, de los ocho prelados que ocuparon las diócesis catalanas, en tanto que la sede tarraconense se encontraba vacante, tan solo parecen haber cobrado relevancia en el relato histórico los testimonios y actuaciones del obispo Gregorio Parcero y Pedro de Santiago, titulares de Gerona y Lérida, respectivamente.

Por esta razón, pretendemos ahora recuperar la voz y testimonio de otros obispos igualmente elocuentes en su ministerio y en sus relaciones institucionales en medio del conflicto surgido. Tal es el caso de los obispos de Solsona, Diego Serrano de Sotomayor y José Lainez, así como de Francisco Pérez Roy, titular de Elna-Perpiñán. Ellos, dentro de la horquilla temporal que abarcan los años de 1635 y 1642 , arrojaron una voz que hoy nos permite descubrir a hombres a cultivados y socialmente bien posicionados, que retratan la situación política y eclesiástica del Principado de Cataluña y, con ello, la de toda la sociedad que les rodea; marcada y determinada por las consecuencias de la política económica del gobierno de Felipe IV, la apelación al usaje del Princeps namque, las relaciones del Ejército con la población civil o la militancia dialéctica mantenida en la conocida como Guerra dels papers, que alimentará ideológicamente la deriva del conflicto.

\section{EL ORIGEN DEL CONFLICTO: LA IGLESIA Y EL PAGO DE LA DÉCIMA}

«Durante el corto espacio transcurrido entre las alteraciones de Évora y la revolución de Cataluña, las armas francesas se habían agolpado varias veces á nuestras fronteras con encarnizamiento, procurando herir á España en el corazón.$^{3}$ Con estas palabras, Antonio Cánovas del Castillo retrataba la situación general en el reinado del cuarto de los Felipes de la Casa de Habsburgo en España. Un país que hacía aguas y veía amenazada su integridad como consecuencia de una funesta crisis que se extendía más allá de los flancos de la política exterior e interior, y cuya raíz se encontraba en la asfixiante situación económica. Más allá de las fronteras de la Monarquía Hispánica, se batía con las principales potencias europeas para mantener la hegemonía de España en el exterior. Desde dentro, la presión fiscal y la carestía no solo cuestionaban abiertamente las acciones del valido real, sino que pretendían su desgracia: «iViva el rey, muera el mal gobierno!».

Desde 1635, los ejércitos españoles se encontraban desplegados por Europa. La necesidad de mantener la preeminencia política en el continente obligaba a medirse con el resto de potencias en varios frentes simultáneamente, todo ello a la vez que España revalidaba su posición como paladín de la religión católica frente al protestantismo y algunas corrientes consideradas igualmente heréticas. De esta manera, se intervino en el conflicto sucesorio de Mantua, con el fin de asegurar la hegemonía de las rutas comerciales del Camino español; en el frente alemán batallaban los ejércitos del cardenal-infante Fernando de Austria; en Flandes se reabría el conflicto tras la ruptura de la Tregua de los Doce años; y, en Italia, también, las tropas de Juan José de Austria procuraban sofocar los amotinamientos y revertir la proclamación de la república napolitana a instancias de los franceses. Una agitada política exterior que abría las puertas a un conflicto interno.

El dispendio económico de la guerra, a cargo de las arcas públicas, hizo cuestionar la malograda salud del erario. Las Cortes de Castilla empezaban a desesperar. Ya no solo no se obtenía el resultado esperado con las recaudaciones, sino que, además, ahora se empezaban a crear nuevos tributos a algunos productos básicos, con el consiguiente descontento popular; y todo ello a la vez que se veía cómo el vellón iniciaba una progresiva devaluación. ${ }^{4}$ Por su parte, el vulgo, hastiado y encendido por las cada vez más onerosas cargas fiscales, se encontraba al borde del colapso: se sucedían las levas para acudir al frente, a una guerra que quedaba muy lejos de sus fronteras, sin claros atisbos de percibir los honorarios previstos; mientras que sus impetraciones y rogativas, a la espera de que el cielo trajera agua y prósperas cosechas, parecían tener el silencio por respuesta.

La alerta social era creciente, el colapso advenía. La política recaudatoria iniciada por el conde-duque de Olivares empezó a tener contestación en todas las latitudes peninsulares: algunas veces, de un modo organizado; otras, en cambio, surgía de un espontáneo descontento popular. Vizcaya acogió protestas entre 1631 y 1638. En el reino de Aragón, y en conexión con los sucesos de Cataluña, los altercados se concentraron entre 1647 y 1648. Lo mismo que en Andalucía donde, por estos años, se hicieron presentes los conflictos: en Granada, en 1648, se produjeron amotinamientos por la inflación del trigo hasta en un trescientos por ciento; al igual que en Córdoba o Sevilla a principios de la década de los cincuenta por la desproporcionada subida de precios.

En medio de este contexto político, económico y social, marcado por la crispación y una tensión pujante, determinados círculos de la aristocracia se atrevieron a poner en jaque al valido real; dando lugar al surgimiento de intrigas y conspiraciones contra la figura del conde-duque, como descuella de las actuaciones promovidas en Aragón por el duque de Híjar o en Andalucía por el duque de Medina Sidonia.

Sin embargo, mucha mayor trascendencia, por su repercusión histórica, han tenido los sucesos ocurridos en Portugal, que derivaron en la secesión de la corona española; o los que tuvieron lugar en Cataluña, a los cuales habremos de referirnos seguidamente.

\footnotetext{
3 Cánovas del Castillo 1888, 112.
} 
En medio de esta compleja ecuación no podemos - ni debemos- olvidar el posicionamiento de la Iglesia española, quien también vio amenazada su economía por mor de las nuevas tasas que Felipe IV imponía a sus rentas. A las conocidas como tres gracias (cruzada, subsidio y excusado), no exentas de polémica en su momento, se sumaba ahora un nuevo tributo, la décima, que autorizaba a la Corona, por un breve de Urbano VIII de 5 de febrero de 1632, a percibir hasta un máximo de seiscientos mil ducados, exigibles a todos los curatos titulares de rentas de más de cien ducados y a todos los beneficios de renta superior a veinticuatro ducados. No tardaron en llegar las protestas, ni tampoco los recelos, con incluso conatos de violencia; ${ }^{5}$ y especialmente cuando, por la dificultad de averiguar con exactitud qué rentas sí debían estar gravadas y cuáles no, se determinó que la imposición se realizara sobre todas ellas.

No obstante, de entre todos estos episodios, el que mayor relevancia pareció alcanzar, por los tumultos ocasionados, las algaradas que se sucedieron y la tensión diplomática generada, fue la que tuvo lugar en el Principado de Cataluña. Y es que, lejos de acceder al pago, los cabildos catedralicios -los más afectados por este impuestomediaron en primera instancia con la Diputación del General para que fuera este órgano quien abogara por los intereses de la Iglesia. ${ }^{6}$ El Brazo eclesiástico recibió el memorial de los capitulares donde no solo exponían la ilicitud de este impuesto, sino que también les recordaba a los diputados la pena de excomunión a la que quedaban expuestas sus señorías si actuaban contraviniendo el derecho foral:

Se adverteix que, en moltes constitucions està disposat que las personas eclesiàsticas, de ses rendes, no paguen ni donen les servituts que dites constitucions mencionen, disposant també que la magestat real deu deffensar les immunitats, prerrogatives, excempcions y demés privilegis, no sols dels eclesiàstichs, en orde a ses persones, però de sos béns, no suffrint se'ls pose pecha alguna, ab les extencions, que ab ditas constitucions, privilegis y altres concessions se conté. De a hont resulta que, si vostra senyoria, cooperant ab la forma que sa magestat mana, escriurà per tal imposició a sa Sanctedad, directament vindria contra ditas disposicions, tant favorables e, per consegüent, per dita violació incidirian en la sentència de excomunicació y, així mateix, contrafarian al jurament que tenen prestat en lo ingrés de sos officis. ${ }^{7}$

De esta manera, mientras por un lado buscaban el posible amparo de las instituciones civiles y también de las eclesiásticas, como la Nunciatura Apostólica o la Santa Sede, los propios capitulares exhibían una conducta beligerante ante las autoridades del rey que procuraban la recaudación de la décima. Fue esto quizá lo que motivó que algunos historiadores considerasen estas actitudes, y los actos que promovieron en consecuencia, como «conatos de rebelión, alentados desde el púlpito y jaleados o apoyados por una parte de la población». ${ }^{8}$ Y es que, mientras Barcelona, Elna y Tarragona

5 Las protestas de la Iglesia española se materializaron de forma aislada, pero con fuertes muestras de tensión, en Sevilla, Salamanca, Osma o Murcia, por citar solo algunos de los ejemplos que recoge Domínguez Ortiz (1970, 155-157).

6 Torres 2012b, 33.

DGC 1613.

8 Torres 2012a, 887. mantuvieron un relativo orden en su seno, diócesis como las de la Seo de Urgel, Lérida, Gerona o Vic mostraron la cara más feroz y activa del conflicto: el obispo Parcero, colector de la décima, amenazó con excomulgar a los eclesiásticos díscolos y se vio forzado a trasladar la sede episcopal de Gerona a Bisbal del Ampurdán para intentar reconducir la situación. ${ }^{9}$ En Vic, los alguaciles reales fueron apedreados a su llegada, los jueces de la Real Audiencia ignorados por las dignidades eclesiásticas, quienes cerraron las iglesias a su paso; incluso una compañía de doscientos cincuenta soldados que se dirigía hacia el Rosellón fue masacrada a su paso por la región ausetana. ${ }^{10}$ Lo que se había iniciado como una protesta eclesiástica empezaba ahora a alumbrar un contingente beligerante mucho más amplio, de tipo popular.

La imposibilidad de retrasar más la exacción de la décima propició la búsqueda de una solución interna al conflicto, como dan prueba los concilios convocados en la provincia eclesiástica de Tarragona en 1636 y 1640. La Iglesia catalana se reunía ante "la urgente ocurrencia de negocios que afectaban a todo el clero y al estado eclesiástico, y muy singularmente sobre la ejecución de las gracias del subsidio y el escusado» que el papa había concedido al monarca español. ${ }^{11}$ No obstante, las circunstancias no impedían que otro tipo de cuestiones entraran a formar parte del debate y de las discusiones conciliares. Se dejaba ver, pues, cómo el trasfondo de la cuestión no era en sí mismo hacer prevalecer los intereses de la Iglesia, sino satisfacer los intereses particulares de una representativa facción de clero, como eran los miembros de los respectivos cabildos capitulares. Así, en uno de los suplicatorios presentados se mostraba el recelo que buena parte de estas dignidades tenían de que alguien ajeno a la élite interestamental catalana interfiriera en estos oficios, privándoles de sus beneficios y del correspondiente inicio de un probable cursus honorum dentro de la carrera eclesiástica. ${ }^{12}$

La posición encontrada en el seno del concilio debió venir determinada por las alocuciones de los prelados asistentes. La condición regalista de los obispos haría virar en los debates las opiniones contrarias a la décima hacia las demandas exigidas por el rey. Así, al menos, pareció actuar Diego Serrano, titular de Solsona, de quien cuenta Salmerón que se «esforçó esta parte en quanto pudo, y con razones tan vivas dignas de su gran caudal, que se consiguió lo que se pretendía [...], obrando en todo como fiel vasallo y agradecido», pues "aprendió a saber ser súbdito de su Rey, y servirle en las ocasiones en q[ue] representa necesidad $॥ .{ }^{13}$

En cualquier caso, y para este tiempo, la situación política de Cataluña mostraba la peor cara posible. La escalada de tensiones entre el gobierno de Felipe IV y las instituciones del Principado parecía estar llegando a sus últimas consecuencias, sin que los actores políticos que las representaban pareciesen estar dispuestos tampoco a rebajar la crispación. Y es que precisamente los que en otro momento

\footnotetext{
9 Ibídem, 44-46.

10 Elliot 1976, 258.

11 Madurell 1948, 121.

12 «En lo pressent Principat de Catalunya y esta provincia de assi en havant no pugan esser officials ni vicaris generals que no sien cathalans y naturals del present Principat y comptats de Rosselló y Cerdanya». Sessió XX, en Processus iuris ecclesiastici... 1929, 34.

13 Salmerón 1646, 461.
} 
fueron instigadores de la rebelión eclesiástica — como la denomina Torres $-{ }^{14}$ habían conseguido abrirse un próspero camino más allá del clericato en la vida civil y ostentaban ahora cargos de máxima representatividad pública. Así, el tono elevado de sus homilías se trasladaba asimismo a los parlamentos hechos en la Diputación del General. A las simples reivindicaciones económicas se sumaba entonces también, como fruto de las circunstancias, una respuesta ante los abusos que, a lo largo y ancho de Cataluña, las tropas de Felipe IV estaban perpetrando. Enfrente, los obispos, quienes, ante lo inevitable, seguían pidiendo fidelidad y obediencia al rey:

Senyors, rei tenim y pare, no sols cristià sinó catòlic de renom; com major sigui la nostra justícia, en la mateixa mesura ha de créixer la nostra confiança, agenollats exposem-li la nostra misèria i que parli solament la nostra fidelitat. [...] Justifiquem la nostra causa amb Déu, sa majestat i les gents, aquest és el mitjà de la tranquil.litat y de la pau [...]. ${ }^{15}$

«PROMPTOS DE ACUDIR AL SERVICIO DE SU MAGESTAD»: PRELUDIO DE UNA CRISIS

La Guerra dels Segadors y sus consecuencias en el Principado, aun teniendo un sólido componente social y siendo promovida en parte por los intereses político-económicos de las élites interestamentales, no puede desgajarse de los importantes acontecimientos políticos que en esos mismos años estaban teniendo lugar en Europa y, singularmente, en el seno de la Monarquía Hispánica. Y es que, más allá de las causas y concausas de carácter interno - regional y nacional-, cabe observar cómo los frutos del conflicto catalán tienen como marco referencial las disensiones de la diplomacia franco-española de la primera mitad del siglo XVII.

Cuando aún no parecía seca la tinta de la Paz de Cherasco (1631), por la que se resolvía el conflicto mantuano, en 1635 España amanecía con una declaración de guerra por parte de Francia. Ni siquiera el papa Urbano VIII, como tampoco las nunciaturas de ambos países, pudo mediar ante posturas tan enfrentadas. De algún modo, los intereses contrapuestos de ambas coronas, así como la enemistad pública entre Olivares y Richelieu, parecían buscar la ocasión para medir sus fuerzas. Tanto es así que, como guiados por la máxima latina del Si vis pacem, para bellum, desde 1632 ambos países habían estado trabajando para responder a un eventual conflicto armado.

1634. Las previsiones de una inminente guerra con Francia llevan al virrey de Cataluña, Enrique de Cardona, a controlar desde el condado del Rosellón cuál era el estado de los ejércitos en Francia. La situación parecía requerir de una reorganización en las defensas de las plazas fronterizas, así como de una leva que empezara a movilizar al Ejército en el Principado, pero la compleja situación interna no facilitaría el asunto. Y es que la diplomacia del gobierno real con las instituciones catalanas se encontraba francamente enquistada, con diferencias plausibles; y no solo en la gestión de la crisis económica, sino también en lo que empezaba a perfilarse como preparativos para la guerra franco-hispana, desde la exacción de los quintos (quints) y de la décima a la inversión que la poliorcética demandaba. Los intereses políticos, de otro lado, situados los unos enfrente de los otros, tampoco abonaban las condiciones para el diálogo. Porque, habiendo dado al traste con la Unión de Armas, el conde-duque de Olivares exigía más de los catalanes en lo económico y en lo militar; y estos, a través de la Diputación del General, se acogían a fueros y prerrogativas de antaño que les permitían eludir todas aquellas demandas que procedían del valido. Así ocurrió, al menos, en 1634, 1637 y 1639, cuando se apeló al usaje del Princeps namque, con el fin de reclutar más efectivos con los que guarnecer las defensas del Languedoc, y se obtuvo una negativa por respuesta. Algo que Felipe IV consideraba como una falta de compromiso y fidelidad con la causa:

La dilación con que he entendido que procedeis en la leva de gente para la defensa de esse Principado me obliga a estrañar mucho que falteis tanto a vuestra obligación, con tan conocido daño de mi servicio y riesgo de la opinión de vuestra fidelidad. [...] Otra vez os he advertido de esto mesmo y el conde de Sancta Coloma lo ha hecho también por su parte y de la mía, y aunque devo esperar [...] que obrareis como devéis, si tan advertido no lo hiciéredes, mandaré poner el remedio que convenga. ${ }^{16}$

Este enconamiento, fruto de una verdadera crisis política, estaba mostrando otros perfiles igualmente problemáticos desde la perspectiva cortesana, los cuales se traducían en la falta de colaboración o de compromiso de las instituciones catalanas con todo lo referente a la salvaguarda de los intereses de España en la guerra contra Francia. Vistas las hostilidades que empezaban a darse en la frontera, el duque de Cardona remitía el 22 de noviembre de 1634 una misiva a los diputados de la Generalidad para que librasen «vuestras señorías una buena cantidad de lo que se queda deviendo en essa Deputaçión, de la fábrica de castillos para los de Perpiñán y Salsas», para que, como mandaba el rey, esos "y los demás puestos neçessarios que abrigan essa provincia, estén fortificados». ${ }^{17}$ Las contribuciones que se hacían parecían no ser suficientes; de ahí que en octubre de 1636 , como también se había hecho en febrero de 1635 , se instase a los diputados a que, ante «la gran necessitat tenia de fortificació lo castell de Perpinyà», hicieran lo posible en atender a lo «que restava de las cent mília liuras que en las Corts del any 1585 foren reservades per fortificacions de fortalesas». ${ }^{18}$ Así, para junio de 1637 ya se habían invertido ocho mil libras y mil escudos.

Estas aportaciones quedaban lejos de las expectativas que la Corte se había hecho al respecto. El Consejo de Aragón daba vía libre a que el rey promulgara una real pragmática en noviembre de 1638, por la que «ordenamos, dezimos y mandamos que en los dichos principado de Cathalunya y condados de Rossellón y Cerdaña se hagan las fortificaciones de la manera y en la forma que están dispuestas y ajustadas de nuestra orden en un memorial que hemos remitido

\footnotetext{
14 Torres 2012b, 32.

15 Sanabre $1968, \mathrm{~s} / \mathrm{f}$.
}

$\begin{array}{ll}16 & \text { DGC, } 964 . \\ 17 & \text { Ibídem, } 1681 . \\ 18 & \text { Ibídem, 684. }\end{array}$ 
al conde de Santa Coloma». Una disposición que el nuevo virrey, Dalmau de Queralt, dio a conocer en enero de 1639 y que, nuevamente, volvió a suscitar la firme oposición de la Generalidad. En audiencia con el virrey, el Brazo militar aludía que «lo present principat de Cathalunya y los poblats en aquell son poble, líbero, franch y exempt de tota contribució forçada»; y que, en virtud de esto, "sie servit revocar dita pragmàtica y crides en observança de las generals constitucions, capítols de Cort, privilegis, usos y costums de dit Principat». ${ }^{19}$ No se trataba de un dispendio ni de un mero capricho. Las exigencias que procedían de la Corona quedaban fundamentadas en la necesidad de garantizar la resistencia de las plazas del Rosellón y la Cerdaña ante un posible ataque o asedio por parte del ejército francés, similar al que había tenido lugar en Fuenterrabía en 1638. El propio Olivares le confesaba a Santa Coloma: «No es mi animo quando hago estos presupuestos proponer a V[uestra] S[eñoría], aunque en forma de discurso, que acometa a los enem[ig]o[s]. [...] mi propos[ici]ón es defender que no se llegue a sitio». ${ }^{20}$ De ahí que, ante la persistencia de las autoridades catalanas a sujetarse a las disposiciones del derecho consuetudinario, el conde-duque buscara nuevos resortes a través de los que obtener las contribuciones necesarias para sacar adelante la empresa. La sujeción de los pastores diocesanos a la regalía que les había concedido la mitra posibilitó su colaboración en la recaudación para la restauración de las fortificaciones. Desde la diócesis de Solsona, el prelado mercedario Diego Serrano de Sotomayor ${ }^{21}$ atendía a las demandas que se hacían desde la Corona para la defensa y socorro de Cataluña, aunque no sin ciertos problemas. Y es que, aun desarrollando una encomiable labor pastoral, sonados habían sido los desencuentros entre el obispo y sus canónigos, no solo por la provisión de un canónigo de origen castellano, sino por los apercibimientos que tuvo que trazar por disputas surgidas en el seno del cabildo, con motivo de la supuesta malversación y apropiación de fondos por los canónigos, así como por "sacar pistolas para matarse». ${ }^{22}$ La situación política también debió de incomodarle sobremanera, barruntando incluso el desenlace que tan solo un año más tarde iba a sacudir Cataluña. Y es que, estando en Lérida en la primavera de 1639, según conocemos por la correspondencia mantenida con el conde de Santa Coloma, se dirigió a la Corte por carta, donde solicitaba «socorro de oraciones a todos los obispos de España para el feliz suceso de las armas». ${ }^{23}$

Así, como decimos, la contribución de Serrano a la causa, y en nombre de la diócesis, fue cuando menos discreto, ya fuera por obstinada resistencia o falta de medios, ya que los eclesiásticos solsonenses evitaban contribuir al servicio para las fortificaciones: «Me manda V[uestra] E[xcelencia], mande a mis Vicarios Generales y officiales con pena a los ecclesiassticos de esta diocesi[s] a que paguen el servicio

\footnotetext{
19 Ibídem, 919.

20 ACA. Generalitat, doc. 5028, f. 4v.

21 Diego Serrano de Sotomayor, O. de M. (1578-1652.), nacido en Chillón (Córdoba), fue general de su orden, calificador del Santo Oficio y obispo de las diócesis de Solsona, Segorbe y Guadix, donde murió; y preconizado como titular de Tortosa y arzobispo de Valencia, cargos a los que renunció. Garí 1875, 287.

22 AHDS. Actas Capitulares, leg. 25h, doc. 5177; leg. 254, doc. 25h, pliego suelto, f. $2 \mathrm{v}-4 \mathrm{v}$.
}

23 Costa 1959, 384. para las fortificaciones por vía del fogages y aunque lo doy por justificado sería Señor conveniente que todos los Prelados nos conf[...]amos en la execucion».24 Asimismo, excusaba Serrano los parcos donativos que llegaban desde su diócesis ya que «la pobressa desta tierra es tanto, así en lo secular como en lo ecclesiastico, [que] no [h] hallado quien de presente me socorra», ${ }^{25}$ puesto que "la pobresa desta Iglesia es la mayor de todo el Principado, y la gente tan necessitada, que si el Obispo no los remedia de ordinario, perecen». No fue óbice, sin embargo, para que el obispo respondiera con lo que buenamente la economía le permitía: "Señor, [h]e juntado, como Dios sabe, quinientas libras con que sirvo a Su Mag[esta]d. y quisiera según mi afecto fueran quinientos millones». El virrey, por su parte, le respondía agradecido, más aún después de los desaires y desplantes que acostumbró a recibir de una clase política que fue tornándosele en contra:

Con lo que he recibido de V[uestra] S[eñoría] de 1 de este [febrero de 1639] veo quan generosamente sirve a Su Mag[esta]d. en la contribución de las fortificaciones [...] y en consequencia de lo que reconozco dever le doy a V[uestra] S[eñoría] las gracias y daré a Su Mag[esta]d. cuenta del gusto con que sirve en la ocasión presente y de los deseos que le quedan de poderlo hazer con maiores ventajas. ${ }^{26}$

El servicio del obispo a la causa se tradujo también en la aportación de tropas mediante una modesta leva de cinco soldados, realizada en julio de 1638 , que se sumaba también a la realizada en los «castillos y baronías de esta mitra». Esto es lo que le llevaba a Serrano a considerar ante el virrey cómo el servicio que se hacía a la Corona desde «este Obispado es muy poco, y muy tenue; pero hacen lo que pueden, y están en esta disposición para ponerlo por obra siempre que lo mande V[uestra] Ex[elenci]a»; aun así los soldados «de esta Mitra, que es la tercera parte de esta Ciudad [Solsona], responden que están promptos de acudir al servicio de Su Mag[esta]d. [...] siempre y quan[do] les sea mandado». ${ }^{27}$

Otros quinientos escudos parece ser que dispensó Bernardo Caballero, obispo de Lérida, para las defensas del Rosellón, y que fueron entregados directamente al prelado de Elna, Francisco Pérez Roy, juntamente con otros quinientos que ofreció el titular de Barcelona, García Gil de Manrique. Grave debía de ser para entonces la situación, pues el 29 de enero de 1639 conminaba Pérez Roy al conde de Santa Coloma a recabar cuanto dinero fuera posible para la defensa del Rosellón: "Se sirva ponderar las raçones que me parecen obligar a que siendo lo que V[uestra] S[eñoría] hisiere de tan notable consequencia para que los demás se ajusten a lo que es tan del servicio de Dios y de Su Mag[esta] d. procure vencer cualquier dificultad, assi lo espero». ${ }^{28}$

Así, mientras tanto, la tensión institucional crecía entre la Corte y la Generalidad a medida que el foco de la guerra

24 ACA. Generalitat, doc. 4210, f. 1. El subrayado es nuestro: el fogatge o fogaje fue una carga impositiva propia de la Corona de Aragón, entre los siglos XIII y XVIII, que gravaba una cantidad específica sobre un fuego $u$ hogar por cada vivienda.

25 ACA. Generalitat, doc. 3955, f. 1.

26 Ibídem, doc. 3578, f. 1.

27 Ibídem, doc. 2185, f. 1.

28 Ibídem, doc. 3511, f. 1-1v. 
empezaba a virar hacia el condado rosellonés. El refuerzo de las defensas de las plazas estratégicas de Salses y Perpiñán parecía constituir una necesidad de primer orden, juntamente con la provisión de efectivos que guarnecieran dichas defensas. Así, mientras las Cortes de Aragón parecían contribuir en la medida de lo posible con la exacción de "quatre mil quatre centes sinquanta sinch lliures, sinch sous y sis diners de moneda barcelonesa» en concepto de fogajes, ${ }^{29}$ los diputados del General, ante las prescriptivas notificaciones que llegaban del palacio virreinal, persistían en eludir el mandato real de percibir cualquier recaudación para este tipo de trabajos, acogiéndose a las interpretaciones que ofrecían los antiguos ordenamientos jurídicos del Principado y evitando así cualquier tipo de colaboración en este asunto. Algo que, nuevamente, motivó la exasperación del propio Felipe IV:

El Rey. Diputados: Del conde de Santa Coloma ha entendido la embaxada que le havéis hecho sobre la publicación de la pragmática de las fortificaciones con pretexto de ser contra constitución. Y hame hecho grande novedat esta acción tan voluntaria, pues siendo vosotros los que con más atención deviáredes mirar por la defensa desse Principado, y que se halla en tan grande aprieto, no sólo él sino toda España, quando la materia tuviera alguna duda antes de empeñaros en instancias públicas que tanto mueven inquietudes deviérades haver usado del medio de la conferencia con mas ministros, porque si bien en los casos de la defensa pública no ay disposición que pueda escusar los medios de assistir a ella, yo por mi clemencia que he querido ajustarme a las mesmas disposiciones de las constituciones por lo que siempre ha desseado su observancia. $Y$ assí espero que desistiréis de vuestro intento pues no puedo faltar a la obligación que como rey y señor natural dessa província me incumbre de mirar por su según estado y defensa, esperando de vosotros que como tan fieles vassallos assistireis como devéis a lo que os tocará. Dattus en Madrid, a XIX de enero, MDCXXXVIIII. Yo el Rey. ${ }^{30}$

\section{EL FRENTE DEL ROSELLÓN Y EL OBISPADO DE ELNA}

En el verano de 1639 las maniobras militares empezaban a concentrarse en los límites del Principado de Cataluña. El ejército francés empezaba a desplegarse en las posesiones del Languedoc-Rosellón bajo el mando del mariscal Frédéric-Armand de Schomberg y de Enrique II de Borbón, príncipe de Condé. Para entonces, y no sin razón, la tensión parecía máxima. Las inquietudes del conde-duque se basaban en no saber si las guarniciones y los efectivos concentrados tanto en aquellas plazas como en las de la frontera permitirían aguantar los envites de los franceses; esperando que esto le ofreciera el margen necesario para iniciar, por otro lado, las campañas previstas: desde Italia, enviando hacia el Rosellón los destacamentos allí desplegados; desde Fuenterrabía, combatiendo las plazas más próximas con los infantes que allí quedaban; y enviando desde La Coruña entre siete y ocho mil hombres con destino a Flandes, para atacar a Francia desde el norte, juntamente con los efectivos que ya se encontraban allí.

\footnotetext{
29 DGC, 1822.

30 Ibídem, 929-930.
}

"Señor, ya tenemos cerca al enemigo», escribía Santa Coloma el 9 de junio de $1639 .{ }^{31} \mathrm{Al}$ día siguiente, cumpliendo los peores presagios del valido, empezaban a caer las primeras plazas españolas a manos de las tropas de Schomberg, con veinticuatro mil infantes y cuatro mil caballos. ${ }^{32} \mathrm{El}$ cabo encargado de la custodia del castillo de Salvaterra (OpoulPérillos) entregaba la guarnición sin defenderla, lo que conllevaría un castigo ejemplarizante. El objetivo militar era ahora resistir en Salses hasta poder disuadir al enemigo:

La ocasión no es dudar ni de esperar un suceso como el de Opul (de cuyo castigo doy a V[uestra] S[eñorí]a infinitas gracias) y le supp[li]co y protesto que sin humano respecto quite, ponga y assegure; y quexese quien se quexe, que más vale que se quexen ellos que lo lloremos todos. Salsas, como plaza la más empeñada de todas, es la q[ue] V[uestra] S[eñorí]a tenga más proveida que todo lo demás, y de mejor gente, pues ha de ser la q[ue] ha de deshacer el exercito del enemigo en su primer ímpetu y resistirle hasta que enflaquecido él y engrossados nosotros podamos hacerle lo que en Fuenterrabía. ${ }^{33}$

Mientras tanto, desde Barcelona llegaban quinientos hombres más para sumarse a las tropas ya dispuestas en todo el Rosellón y la frontera. Perpiñán, por medio de sus cónsules, pedía también socorro a la Diputación del General a la vista de las diligencias recibidas por el ejército francés. Así, el 28 de junio de 1639, los diputados «manaren arbolar la bandera de sant Jordi per a anar continuant la leva dels soldats [...] fins sie cumplert lo número de las companyias que ses senyories tenen intenció de fer».${ }^{34} \mathrm{El} 11$ de julio, dos mil quinientos soldados catalanes se sumaron a los ocho mil efectivos de los tercios ya dispuestos en Salses, combatiendo cuanto pudieron el asedio de Condé y al ejército episcopal movilizado por Richelieu. ${ }^{35}$ El marqués Gaspar Toralto, encargado de la defensa de la plaza, se rendía el 19 de julio después de haber cedido la muralla y haber entrado el enemigo en la ciudad.

Con esta derrota se consolidaba lo que Sanabre consideró como la "semilla de la futura guerra civil». Los sucesos daban paso a un serio cruce de reproches y agravios entre las instituciones cortesanas y catalanas, que recrudecía aún más las tensiones de los últimos años. Se sumaban a esta discordia las derrotas que las tropas de Felipe IV obtenían en el frente y también los altercados que, fruto de estas disensiones, se suscitaban tanto en el ejército como en la población. Así, por un lado, las tropas - de diferentes nacionalidades y procedencias - se enfrentaban entre sí, culpando a los catalanes de no luchar con valentía y acusándolos de desertores; y por otro lado, fruto de la falta de disciplina del ejército realista y de lo mal pagadas que se encontraban sus tropas, en las ciudades donde se alojaban, estas cometían excesos y abusos que se convertían en verdaderos atropellos. Hechos que documenta Sanz en todo el todo el Principado durante estos años, fruto de estas circunstancias así como

31 ACA, Generalitat, doc. 4779, f. 1.

32 Valladares 1790, 37.

33 ACA, Generalitat, doc. 5028, ff. 2-2v.

34 DGC, 959.

35 Sanabre 1985, 32. La política Iglesia-Estado, como en España, formó parte del marco de actuación en la Francia de Luis XIII, donde el cardenal Richelieu puso a disposición del Ejército las tropas movilizadas por el arzobispo De Rebé y los obispos de Daillon du Lude, Cruzy de Marillac, Fenouillet, Denis Cohon y La Baume de Suze. 
del «estado de penuria y necesidad» en que se encontraban los milicianos. ${ }^{36}$

Seis meses duró la campaña de Salses, hasta que en enero de 1640 la plaza fue recuperada al comandante Roger de Bossost. Para entonces, en el frente, el ejército español había sufrido entre siete y ocho mil bajas, fruto de un brote de peste. El estado de las tropas y el curso que, en líneas generales, alcanzaba la guerra empezaban a enfriar las negociaciones de paz que, desde el principio y de forma secreta, Richelieu y Olivares habían mantenido. No obstante, y más allá de los márgenes de la política general, con la guerra florecía tal suerte de miserias que hacía impracticable la vida en las ciudades situadas en los frentes de bataIla. A escasos dieciocho kilómetros de Salses, Perpiñán, por medio de sus dirigentes, daba muestra de lo que allí ocurría. Escribía el obispo Francisco Pérez Roy ${ }^{37}$ a Santa Coloma para que mediara de la manera que fuera posible para evitar la masificación de los hospitales y cárceles de la ciudad: no solo pedía dinero para poder abastecerlos, ${ }^{38}$ sino que se buscase solución a los cadáveres que empezaban a hacinarse, tanto de personas como «de cavallos y otros animales que se ve que los [h]ay». En este mismo escrito, de 13 de octubre de 1639 , se daba cuenta de los soldados enfermos, para quienes se pedía una igual solución. Si ya no podían combatir, ¿por qué no los enviaban a sus hogares?; si por sus desmanes habían sido condenados, ¿no había otra solución para ellos más allá de la cárcel? Sugería el obispo que, de ser posible, su pena fuera condonada y, de no serlo, los enviaran a galeras. Lo que fuera con tal de no dejarlos en las cárceles. De esta manera «no perecerán en la carzel de hambre, ni morirán rabiando y como desesperados sin amparo, y muchos sin sacramentos como se ha visto por no pedillos a tiempo"; se evitaba, al menos - como estaba ocurriendo en Salses-, «el peligro de peste y contagio en las cárceles que en ellas suelen comenzar como se ha visto». ${ }^{39}$

Las quejas del obispo Pérez Roy se expresaron asimismo en el Consejo de Perpiñán, donde el prelado se lamentaba de cómo en la villa «solo se oyen lloros y llantos lastimossísimos que le quebrantan el corazón». En su alegato, suplicaba al regidor que sacase de Perpiñán a la caballería porque «son mas de tres mil y la villa no tiene mas de dos mil casas", lo que obligaba a cada familia a acoger entre seis y ocho soldados, la mayoría enfermos. Ya el problema no era la manutención y el cuidado de estos, sino cómo el campo quedaba sin trabajar y los respectivos oficios de la villa sin atender, ya que los hombres «no se atreven a dexar solas sus casas ni sus mujeres e hijas, y así no quieren acudir á cosa». ${ }^{40}$ Tal era la preocupación por los saqueos, violaciones y pillajes que cometían las tropas allí donde se asentaban.

Sin embargo, el papel del prelado perpiñanés no quedó, únicamente, en lo estrictamente reivindicativo en lo tocante a la situación diocesana, también mantuvo un papel activo en el transcurso de la guerra. Así, participó como

36 Sanz 2004, 10.

37 Francisco Pérez Roy (+1648), nacido en Gandía (Valencia), fue visitador del arzobispado de Toledo, diputado eclesiástico en la Generalidad de Cataluña, obispo de Elna-Perpiñán y Guadix, y propuesto para la mitra de Vic, a la cual renunció.

38 ACA, Consejo de Aragón, leg. 283, doc. 22.

39 Ibídem, leg. 283, doc. 28.

40 Ibídem, leg. 283, doc. 22, f. 1v. intermediario en la inteligencia secreta, recibiendo a los espías franceses; acudió en diferentes ocasiones al campo de batalla; fue secuestrado como objetivo militar por parte del duque de Luy y formó parte de las Juntas de Guerra que tenían lugar, precisamente, en el palacio episcopal. No obstante, entre los episodios más destacados de su pontificado, y lo que da verdadero testimonio de su labor en medio de la crisis catalana, fue la intervención que mantuvo a partir del mes de agosto de 1639, cuando los tercios de Juan de Arce, Leonardo de Molas y Felipe de Guevara se disponían a asentarse en Perpiñán para reforzar las unidades desplegadas con motivo de la campaña de Salses. La misma noche de su llegada empezaron los disturbios.

La motivación de estas algaradas dista según el cronista al que se acuda, pero en lo que sí parecen coincidir es en su resultado: el enfrentamiento encarnizado entre las tropas, entre sí y también contra la población civil. La artillería de Gerí de la Rena empezó a caer sobre la villa de Perpiñán, cuyos templos saquearon y profanaron los soldados, que dejaron todo "tan arruinado como si huvieran passado Moros y Turcos». ${ }^{41}$ Algo que apuntaría también el propio Pérez Roy en un memorial recogido por Enric Riera. ${ }^{42}$ La preocupación del prelado ante estos hechos, en aras de proteger a la población y pacificar la situación, favoreció su interpelación a los soldados por mor de la piedad y la oración:

El Obispo como sintió la muchedumbre de tiros, y el alboroto del pueblo, sintiendo la desdicha, fue a la Catedral, sacó el Santísimo Sacramento, y con su palio, salió por la puerta de nuestra Señora, dexando orden a su Vicario general, que cerrase la puerta, y que no saliesse ninguno, que no se tocasse campana, ni caxa de guerra; y aunque muchas personas pidieron al Obispo no saliese, por el gran peligro que corría su vida, no lo consiguieron, y encomendándose a Dios llegó al lugar del alboroto, a pie, con su vestido corto de Obispo, y con una Cruz en la mano, y el sombrero en la otra, animando con la presencia del Santísimo Sacramento, les exortava, pidiéndosela por amor [a] Dios, y ponie[n]do por intercesora a la Santísima Virgen, y a los Ángeles del cielo. ${ }^{43}$

Hubo quien consideró esta hazaña como heroica y también quien la tradujo en clave política. Así, en una obra poética - dentro del marco de la guerra de hojas volantes que se sucedió en todo el Principado durante la guerra- se hace referencia a este episodio, donde metafóricamente la ciudad de Perpiñán le escribe a su hermana Cataluña sobre cómo se comportan los soldados castellanos y cómo su pastor -Francisco Pérez Roy- Ilora al ver maltratado a su rebaño. ${ }^{44}$

41 Sala $1640,128$.

42 «No hay casa que no se queje de agravios e insolencias notables; que franceses, herejes ni turcos ni calabreses no podían hacer la mitad del daño que hacen en esta villa, y la dejaron para siempre destruida, y así no hay más en esta villa que llantos, que es la mayor lástima del mundo [...]. S.M. me manda que no consintamos pecados, ni agravios, pues mayores que estos no pueden ser, todo son ofensas a Dios y perseguimientos de pobres y enfermos» (Riera 1986, 121).

43 BNE. Ms. 18169, 13v.

44 «Ja no m'estima lo rey, / sos capitans me afligen / y lo bisbe de Urgell [Pau Durán] / tots, ab gran saña me míran. / Lo meu [Pérez Roy] plora y gemega / vent sas ovellas maltractar / de aquestos llops infernals / y que remey no y pot posar / que de mi fassan trincheras / per aver de pelear». Carta que ha enviada la vila de Perpinyà a Cathalunya... 1640, vv. 125-134. 
Sin embargo, no fue esta la última vez que el obispo tuvo que salir a velar por la paz de la diócesis y, concretamente, de la villa perpiñanesa. Ante los sucesos de 4 de junio de 1640 - tres días antes del Corpus de Sangre de Barcelona-, Pérez Roy tuvo que volver a salir a las calles, custodia en mano, para sofocar los amotinamientos:

El quatro de lunio del año de [16]40 se levantó un motín en Perpiñan de gente fascinerosa, alegando, que los que governavan la villa y armas, atropellavan co[n] los aloxamientos, con que se alteró la villa, y los facinerosos tocaron una campana Congeil, y quisieron matar al Governador de la villa, y cónsulos, al Marqués de la Reyna [de la Rena], que governava las armas de $\mathrm{V}$. Magestad; y al Obispo le quisieron quemar sus casas, y para este sacrificio pusieron leña, y fuego junto a la casa del Obispo, el qual mandó encerrado en su casa (para que se cessasse este daño y escándalo) que la Iglesia Catedral, Parroquiales, y Conventos sacassen el Santísimo Sacramento, y con mucha decencia le llevassen por las calles, para sosegar el motín. Y se consiguió.

Similares sucesos ocurrieron en las poblaciones contiguas, como Rodès o Ille-sur-Tet, donde intentó también mediar por la paz Pérez Roy; aunque esta vez, lejos de sosegar los ánimos de la población, desde el vulgo «le tiraro[n] una carga de mosquetería, que fue milagro no matarle». Hubo, en cambio, quien culpó directamente al obispo de haber auspiciado estos levantamientos, quizá no tanto por acción directa como por omisión y falta de capacidad en su respuesta ante los actos de los clérigos instigadores. De esta manera, en una carta de diciembre de 1640, el maestre de campo Juan de Garay reflexionaba sobre el curso de los recientes acontecimientos:

los remedios para que se consigan efectos tan necesarios [como el respeto y la obediencia a la autoridad real] es hacer Personas de su Real mano, de seguridad y confidencia a la fidelidad del Servicio de V[uestra] $\mathrm{M}$ [ajestad] y poner obispo de birtud, letras y yndustria en la que se formen la soltura del clero y Religiosos de los conbentos de la diócesis que entrambos estos dos estados, han llegado a lo ultimo de la sedición y corrupción, porque en el confesionario y en el púlpito no tratan sino soliviantar el pueblo y faborezer los alçados con muchos yerros persuadiendo a lo[s] ignorantes que con la rebelión ganan el cielo. ${ }^{45}$

Asimismo, y una vez estallada abiertamente la guerra civil en Cataluña, hubo también quien, por motivos contrarios, acusó a Pérez Roy de haberse perfilado de forma muy tibia - connivente incluso- del lado del ejército y de los abusos cometidos por los soldados; muy especialmente frente a prelados como Gregorio Parcero, quien, ante hechos similares, no vaciló para excomulgar a las tropas de Leonardo de Molas en los sacrilegios de Montiró y Riudaerenes. Al obispo de Elna-Perpiñán, por tanto, le acusaban de no haber hecho más contra los tercios, pero sí, por motivos menos graves, haber ido detrás de los franceses: «¿Del bisbe d’Elna / que feya bé / quant en campanya ysqué / contra el francés / no avent-hi altra rahó més / que aver penjat / un Christo crucificat / dos soldadots? ». ${ }^{46}$

\footnotetext{
45 AGS, Est., K. 1709, doc. 40, f. 1.

46 Dialogo verdader, gracios y apacible... 1642, vv. 1213-1220.
}

Para ese entonces, poco margen de maniobra le quedaba al obispo para actuar en un sentido u otro. El 22 de enero de 1641 la Diputación del General ponía en manos de Luis XIII de Francia el Principado de Cataluña; tan solo diez días después, el 2 de febrero, Pérez Roy abandonaba su sede episcopal camino de Madrid, «obedesiendo como es raçon al mandato de Su Mg[esta]d que Dios g[uar]de muchos años en que me manda a que acuda a esta corte á cesar de Su Real servicio». ${ }^{47}$ Ese era el destino de quienes habían vestido la mitra en Cataluña: poner rumbo a la Corte huyendo de la guerra, del recelo que sus nombramientos despertaban en un pueblo levantado en armas y del obligado juramento de fidelidad que Francia les imponía. ${ }^{48}$

\section{ENTRE LA ESTOLA, LA ESPADA Y LA PLUMA: LA PUBLICIDAD ECLESIÁSTICA}

Si con motivo de la guerra con Francia, Cataluña había sido la plaza de armas de España, a partir de 1640 pasaba, directamente, a convertirse en el nuevo frente de batalla. Las tensiones y disensiones acumuladas desde 1632 fructificaron de la forma más negativa posible: la sublevación del pueblo catalán contra toda una compleja situación social, la cual adquiría su facción más visible en las cargas tributarias implantadas desde la Corte y en los abusos cometidos por los tercios. Aunque, eso sí, escondiendo tras de esta respuesta violenta una insumisión a las hambrunas, las miserias y los excesos cometidos por las clases señoriales dirigentes. ${ }^{49}$ Una amplia bibliografía existe al respecto de esta cuestión, pero sería necesario señalar, igualmente, cómo lo que empezó siendo una mera protesta popular - con tintes de rebelión- terminó por constituirse en un conflicto mucho más complejo y que ha arrojado diferentes interpretaciones de los hechos. Tanto es así que autores contemporáneos han visto en estos sucesos determinados factores de cariz políticocultural e identitario; que convierten a esta guerra en «una lucha de la comunidad política catalana de tipo nacional $» .^{50}$

En cualquier caso, parece quedar claro que la Guerra dels Segadors y las causas que la propiciaron resultan ser una concatenación de hechos y situaciones, de estrategias políticas y tensiones sin resolver entre diferentes núcleos de poder; alimentadas por una coyuntura económica en ningún caso favorable. Asimismo, y por la capacidad sugestiva de algunos de los actores, como la propia Iglesia, y los instrumentos puestos a su disposición, este conflicto se terminó por incardinar y vertebrar un determinado sentir, que permitió reducir las macrocausas del conflicto a una somera expresión:

[...] en aquest estat que [a]vuy està Cathalunya es lícit als Provincials pendre las armas y resistir als que la invadeixen, y amenassen invadirla [...] que lo estar ab las armas en las mans [es] en defensa de Deu nostre Senyor, de las propias honras, y vidas, y conservacio de las Constitucions, Privilegis, y llibertats de la mateixa Provincia. ${ }^{51}$

\footnotetext{
47 ACA. Consejo de Aragón, leg., 288, doc. 58.

48 Peña 1709, 304.

49 Nadal 1979, 92.

50 Simon 1999, 21.

51 lustificacio en conciencia... 1640, 2.
} 
En estas palabras, en las que se entretejen contundentes soflamas, cabe advertir más allá de su contenido y su argumentario, un nuevo modo de concebir y entender el conflicto armado, donde la dialéctica pasa a formar parte de la estrategia militar. Una cuestión que, lejos de la anécdota, ofrece una nueva dimensión al hecho de la guerra en sí. Y es que, si algo parece haber particularizado a la Guerra dels Segadors es el entramado literario que hace germinar y que divulga a lo largo de toda la contienda; siendo el primer y más genuino testimonio dentro de la historiografía políticoliteraria española, ya que se introduce a gran escala algo que fue progresivamente implantándose en el escenario bélico europeo durante el Quinientos: un múltiple elenco de publicaciones (panfletos, ensayos, homilías, obras gráficas, poemas, autos...) donde se da cuenta del devenir de la guerra y se contribuye al posicionamiento ideológico de los públicos. Por la multiplicidad y riqueza del contenido de estos trabajos, que han abierto una línea propia de investigación, ${ }^{52}$ son muchos los autores que han considerado a esta contienda como un frente paralelo, como una guerra en sí misma: la denominada Guerra dels papers. Una esfera donde la conocida como literatura de cordel se erige como un arma estratégica, compuesta por para y para el vulgo según algunos autores, ${ }^{53}$ pero que contó con intelectuales orgánicos próximos a las elites de poder para conducir el enfrentamiento dialéctico hacia los objetivos deseados: bien enardecer a las masas a favor de la contienda o, por el contrario, ridiculizar los propósitos políticos de la parte contraria y advertir de los errores dogmáticos y delitos en los que incurrían. Aunque, de esta parte, también hubo quien se mostró con relativa neutralidad y consideró esta como una «guerra mal nacida y peor ejercitada». ${ }^{54}$

Así, pues, la palabra puesta al servicio de la ideología empezó a esgrimirse desde 1640 tanto por la Diputación del General, quien influyó en la creación también de nuevas obras, como por autores y editores independientes. Del otro lado, alineados en el frente castellanista $-\mathrm{y}$ no por ello necesariamente olivaristas-, nombres propios que de algún modo podrían haber actuado como verdaderos juicios de autoridad. Tales son los casos de Diego de Saavedra, Francisco de Quevedo o el jesuita Baltasar Gracián quien vivió de primera mano los estragos de la guerra durante los sitios de la plaza de Tarragona. ${ }^{55}$

Sobre la promoción e ideación de textos propagandísticos, Torres expone la singular militancia que en estas lides ejerció el clero catalán, a quien se debe la mayoría del total de estas composiciones. Así, y a tenor de lo que ya referimos anteriormente, se observa nuevamente la implicación directa que la Iglesia tuvo en el curso de la guerra, alimentando ideológicamente a la población y, en algunos casos, luchando junto a ella contra las tropas de Felipe IV. ${ }^{56}$ De los testimonios analizados en este trabajo se desprende cómo, junto a los ataques directos a la Corona, se hacía una honda reflexión sobre los orígenes franceses de Cataluña o incluso su vínculo histórico con la corona del país vecino, sin olvidar

\footnotetext{
52 Cfr. Ettinghausen 1993.

53 Burgos y Peña 1984, 557.

54 Gracián 1653, III: 11.

55 Batllori 1958, 190-191.

56 Torres 2015, 69-94.
}

tampoco los panegíricos, por supuesto, al monarca «Luys el lusto». ${ }^{57}$

Así, mientras el carmelita Josep Pont, el agustino Gaspar Sala, el capuchino Juan Evangelista de Sarriá o el beneficiado Diego Soler fueron algunos de estos protagonistas que alimentaron la oratoria sacra y la literatura bajo un tono hispanófobo, del lado contrario también hubo una facción de la Iglesia que protagonizó solemnes alegatos contra lo que venía produciéndose en Cataluña. Así, por ejemplo, para la causa escribieron el inquisidor Francisco de Rioja, quien en su Aristarco contestaba directamente a la Proclamación Católica de Sala; Alonso Guillén de la Carrera o el dominico Ramón Dalmau de Rocabertí; sin olvidar, claro está, a Alejandro Ros, protonotario apostólico y deán de la catedral de Tortosa, quien se mostró especialmente crítico con la Iglesia catalana por su papel en la rebelión. ${ }^{58}$ Sin embargo, a esta lista cabría sumar la de otro autor que, hasta la fecha, parece haber pasado inadvertido por los investigadores: el obispo electo de Solsona, José Lainez. ${ }^{59}$

Bien podríamos considerar cómo la participación de este fraile agustino en medio de esta Guerra dels papers es, cuando menos, discreta y velada, especialmente si la comparamos con el activismo del agustino Gaspar Sala. Pero sus aportaciones, preconizado ya como prelado catalán a pesar de no obtener nunca la ratificación apostólica, vienen a perfilar de un modo más preciso el comportamiento y la experiencia política de los obispos en Cataluña durante la guerra.

De sus intervenciones podemos entender que su posicionamiento se mantuvo más bien en un sentido teórico que práctico, ya que, a diferencia de otros colegas suyos, nunca debió de pisar el frente ni tampoco entrar en batalla. Sus reflexiones sobre esta cuestión quedaron expresadas dentro de sus principales aportaciones literarias, consagradas a la moral y a la exégesis, pero en las cuales va introduciendo progresivamente reflexiones críticas al respecto de los sucesos del Principado a partir de 1640. Así podemos verlo en dos de sus obras más conocidas: El privado christiano (1641) y El Daniel cortesano (1642).

En la primera de estas publicaciones, la cual dedica y consagra con paroxismo al conde-duque de Olivares, encontramos un Anteologio apologético donde, precisamente,

57 «el recurso de los Pueblos Catalanes en conflicto tan grande solo había de ser a un rey, Luis, que con excelente valor ayuda a Pueblos affligidos. [...] las mejoras de Cataluña son ciertas, pues [...] llenó de cuidados para expugnar herejes, reedificar Templos, restituyr Iglesias, y rentas Eclesiásticas, [...] mejoró a Cathaluña renunciando [a] todos los derechos que podía tener su Corona en Cataluña». Sala 1642, 72-73.

58 «No puedo negar que [h]a perdido el Pueblo de Cataluña á persuasión de muchos Eclesiásticos, que justificaron su sublevación, ya con papeles firmados, ya con manifiestos dañosos, en que se alterava los sucesos, y se mandaban los semblantes a la raçon y justicia, ya con sermones escandalosos, haçiendo que a costa de Dios, cuyo oficio es desterrar los vicios, y corregir los pecados, se cometiesen tan atroces, y tan barbaros delitos. Otros enfurecían la plebe contra la Nació[n] Castellana, asegurándoles que era agradable á Dios esta crueldad, y que haçían obsequio a la Divina justicia, sacrificando bárbaramente tantos inocentes, no solo en calor de la guerra, ó en la furia del primer enojo, sino en el odio frío, saliendo a [la] caza de Castellanos, como si fueran fieras ó venados». Ros 1646, 350-351.

59 José Lainez, OSA (+1653), predicador real, exégeta y obispo de Solsona y Guadix, aunque de la diócesis catalana no llegó a tomar posesión «por estar muy encendidas las guerras de Cataluña». Suárez 1696, 265. 
parece dar cuenta de las realidades políticas de la España del momento, ante la crisis institucional vivida en Cataluña y también ante el rumbo independentista que había tomado el reino de Portugal. Referente al Corpus de Sang y la Guerra dels Segadors, en el epígrafe titulado "Movimientos en Cataluña por algunos vandidos populares» (sic), Lainez empieza a desgajar, basándose en las fuentes del Derecho de la Monarquía, las obligaciones jurídicas y morales del rey, así como las que corresponden a los territorios y súbditos de ellos. Es decir, lo que afectaba directamente al cumplimiento o no, validez o derogación por parte de Felipe IV de algunos de los fueros o privilegios catalanes en medio de la guerra con Francia. Parecía, por tanto, que el obispo solsonés se atrevía a responder directamente a la lustificació en conciencia (1640) publicada por los diputados del General:

Porque a todo discurso humano insistiendo en Ley divina, y humana, los Reyes tienen derecho a derogar con causa las Leyes, a suspender, y dispensar los fueros y privilegios que de su naturaleza son dispensables, derogables; o no le querran Rey, sino esclavo de las gracias que hiziere a sus vassallos, que le hallan poderoso para favorecer e impossibilitado para derogar o suspender. [...] Los tumultuarios y sediciosos forajidos plebeyos, [h] aviendo tomado las armas, antes con atrozidades nunca vistas, executadas en sus Ministros, cometiendo crimen de Lessa Magestad. ${ }^{60}$

Lejos de concluir aquí, y negada la validez de aquel sistema "do ut des» establecido entre el monarca y la aristocracia y las instituciones catalanas, el obispo de Solsona prosigue arremetiendo contra los diputados tras haber acordado el vasallaje ante el rey Luis XIII — «quien adolece en lo que cu[m]ple, y falta en quanto promete»- y cómo la justificación de la rebelión, basada en los tumultos ocasionados por los soldados en todo el Principado, no era motivo alguno para acusar de deslealtad o interés al rey Felipe IV sobre cuanto allí ocurría. En definitiva, según Lainez, de lo que se acusaba a los tercios era lo mismo que los segadores habían hecho con Dalmau de Queralt al estallar la revuelta:

[¿ं]Quién acomete al padre porque excedió el criado? $A[h]$, que son deseos vanos, colores pretendidos, de quien [se] quiere rebelar porque se finjió injuriar. Ningún pretexto escusa la rebeldía. [...] Lo que dicen es copia de lo que hacen. Animal vario es el vulgo, y más con disfraz de segadores que como Recab y Abemad [Baaná] entraron con las espigas en la mano, ${ }^{61}$ por el qué dirán si les encuentran a matar allí al hijo del Rey Saúl, Miseboseph; y otros al Virrey de la Provincia. ${ }^{62}$

Con esta misma contundencia se despacha el fraile agustino en El Daniel cortesano. En esta ocasión, al no tratarse de un panegírico, parece Lainez más comedido en los elogios y en la retórica aduladora al monarca. Quizá no pesara ahora sobre él la sombra del valido a la hora de escribir. Sea como fuere, se vuelve a abordar la cuestión del sometimiento a la autoridad real, esta vez so pretexto del comentario exegético del primer Libro de los Reyes:

No es fácil saber aconsejar a un Rey como ha de castigar una Ciudad rebelada [...]. Tal vez el Príncipe es piadoso quando más severo [...]. Facciones, sediciones y conjuraciones son estrago y polilla de las Monarquías. [...] Los vassallos suelen fabricar su descontento y levantamiento [...] soñando q[ue] son muchos los tributos, quando suele ser estremas las necesidades de los Reyes, y defensa de sus vassallos, [h] aviendo dexado exaustos los tesoros Reales, co[n] las mercedes recibidas, sin advertir q[ue] el Rey ha de dar lo que le sobra, y el pueblo le ha de acudir con quanto le falta, sin alegrar necesidades pretendidas. [...] Los primeros en la rebelión son los que fueron nuevos en la sujeción. Exemplar política trae Tácito con el caso de los Ternestinos. Las penas a los que faltare[n] la fe y obediencia de su Principe no deve ser ligera. Severa y grave sér, si [h] ay alguna igual a la nota de traidor: el César mató de los Celtíberos que se le rebelaron quinze mil, y mucho número hizo prisioneros, que es muerte con pausa; [y] les vedó las armas a todos para siempre. [...] Mas grave pena les impuso a los a Babylonios en una rebelión su Rey, que salió triunfante, haziendo ahorcar a tres mil de los más nobles (maravilla que la nobleza falte a su señor natural). ${ }^{63}$

En esta ocasión, el obispo Lainez no hace referencia explícita al caso catalán, aunque de su contenido cabe extraer claramente una lectura contemporánea al contexto político del autor. Parece condenar claramente el posicionamiento del Consejo de Ciento, quien se mostraba dispuesto a colaborar en la exacción de los quintos siempre que, a cambio, pudiera tener una contraprestación, gracia o privilegio por parte del rey; como quedar cubiertos, por ejemplo, ante la presencia del monarca. Mucho más severo, en cambio, se muestra con las penas aplicables a quienes cometían rebelión o sedición, algo que podría no ser únicamente imputable a los diputados o al clero catalán, sino también al resto de la aristocracia española que venía incitando al pueblo en contra del gobierno de la Corte.

En cualquier caso, para Lainez, estos hechos de lesa majestad tenían su respuesta penal en la justicia ordinaria. No obstante, la justicia eclesiástica, por su parte, también consideraba punibles aquellos actos que no «procurasen la salud y provecho del Rey». Cita así a los concilios toledanos (V, VI, VII, XVII y XVII), en los que se castigaba con excomunión y anatema a los «agressores de tan feo delicto»; y, para los clérigos, "desde el Obispo hasta el de Órdenes menores, o frayle», la privación de la dignidad, reservándose «a la cleme[n]cia Real la execución, o absolución de la pena de lugar y honra». ${ }^{64} \mathrm{Y}$ qué decir de quienes "suelen fabricarse lastimosas desdichas y sediciones, que turban la paz y zozobran la Corte y el Estado, espacioso campo de escritores políticos»: "quan despreciadas son en él los cielos, estas vanidades de burla, naderías de civilidad o policía de los de la tierra, para que estos queden amaestrados». Para ellos pedía Lainez ser «pretendientes de mejor Colonia y Corte en el cielo». ${ }^{65}$

El que fuera obispo electo de Solsona se dirigía, sin duda alguna, a un público muy concreto, tal y como se desprende de la dureza de sus testimonios. Sus miradas se habían posicionado ya no solo sobre la clase política catalana, sino también sobre el estamento eclesiástico. A sus miembros parecía culparles de buena parte de estas actitudes que

63 Lainez 1642, 316-318.
64 Ibídem, 401.

65 Ibídem, 477. 
el propio Lainez consideraba sediciosas, ocultando tras su genérico pensamiento la precisa opinión que debió de merecerle el presidente de la Diputación del General, Pau Claris. No obstante, este tono amenazante, que respondía a unas demandas ideológicas concretas dentro del contexto de la guerra, dio paso a un tono mucho más moderado cuando el rumbo del conflicto empezó a medrar las victorias del frente catalán.

Así, predicando en San Martín del Canigó, en la frontera del Rosellón con Gerona, con motivo del fin de los Sitios de Lérida, el prelado agustino enterraba el hacha de guerra. Sus palabras, ya no desde la lejanía sino a pie de púlpito, se abrían al perdón, al olvido y a la misericordia, pues «no mira Pablo q[ue] negó Pedro a su Rey y maestro. Ni se acuerda Pedro que persiguió [a] la Iglesia Saulo».

Disculpemos lo pasado para hallar consuelo a lo por venir. No puede dexar de aver sido lo que, ni reprobado lo mal [h]echo, pero abrir las puertas del Perdón, proponiendo disculpas con la opression de los auxiliares enormes, injustos è iniquos violentadores de la lealtad generosa y noble, que no ha de imposibilitar la reducció[n] sin hallar disculpa a yerro. [...] De los muchos, algunos vandidos populares (que entre todos [h]ay de todo) y pocos de diferentes clases, saltándose a sí porque verse solos turba el sosiego de todos. Mas una gota de tinta no da color a un mar. Para disculpar, preciso es mirarlo con otra luz, que así hazen diferentes visos las cosas con diversa reverberación. Mirarlo todo por el mejor lado, y se mejorará la vista. S[an] Ambrosio como Santo disculpó a Pablo de quando fue Saulo. ${ }^{66}$

Las prudentes palabras de Lainez, a las que habían dado paso sus encendidos ánimos precedentes, evidenciaban en su distanciamiento la proximidad del fin de la guerra. La exaltación de las pasiones y la brusca interpelación se teñían, progresivamente, de una afable fraternidad que pretendía acoger bajo un mismo abrazo a los bandos enfrentados. La beligerancia de los obispos en medio del conflicto quedaba atrás y, como se testimonia en las palabras del obispo solsonés, se pretendía ahora abrir camino hacia una nueva estrategia política y eclesiástica: la de vertebrar y coser desde la cabeza de las iglesias diocesanas las heridas abiertas en la guerra. Hizo falta, no obstante, algo más que buena voluntad y serenas palabras para hilvanar los retales de la fragmentada sociedad catalana tras el agrio enfrentamiento que se clausuró, tras doce años de conflicto, en 1652.

\section{CONCLUSIONES}

Como se ha visto, en el transcurso de la Guerra dels Segadors -en su génesis y en su desarrollo- la Iglesia tuvo un singular papel como actor político, deviniendo no solo en un agente más del contexto social sino en una realidad partícipe de cada uno de los movimientos que tuvieron lugar durante el conflicto. Una consecuencia más, según Busquets, de las reformas conciliares de Trento con respecto a las competencias del episcopologio así como a las concesiones regalistas hechas por la Sede Apostólica a la Corona española, que permitía que los propios prelados fueran en sí mismos una expresión más del poder del rey y, por tanto, limitadores de la libre acción a la que aspiraban las iglesias locales así como los institutos religiosos. ${ }^{67}$

De los obispos catalanes en el siglo XVII se ha hablado mucho, y no siempre bien ni en términos ecuánimes. Así, las lecturas sesgadas de la historiografía contemporánea se empeñan en trazar un perfil "españolista» de los prelados que fueron preconizados en las diócesis catalanas; ${ }^{68}$ de ahí que, cuando aparecen sus nombres, sea - con honrosas excepciones - para mostrar y señalar los aspectos negativos de sus pontificados.

Lejos de tales análisis, seguimos apelando a la interpretación de los hechos de acuerdo con la perspectiva histórica, entendiendo y ponderando los principios sociales, políticos y culturales de su tiempo, con sus singularidades y particularidades; y otorgando, además, la voz necesaria a todos aquellos personajes o figuras que formaron parte del relato histórico y que, fruto de los testimonios conservados, hoy nos permiten conocer más de cerca la realidad pretérita.

De ahí el interés de nuestra investigación por dar a conocer esas voces calladas y comprobar, de primera mano, cómo determinados obispos - es el caso de Diego Serrano, Francisco Pérez Roy y José Lainez - pudieron y quisieron dar respuesta a cuanto ocurría a su alrededor. Algunos, participando más activamente del contexto político; otros, pausada y quedamente atendiendo a cuanto se solicitaba ellos: en cualquier caso, actuando de acuerdo con su propia personalidad y marcados por las singulares líneas de tensión política y social que jalonaron el conflicto catalán desde sus preludios hasta su etapa final. Quizá fue esto, precisamente, lo que determinó el horizonte pastoral y político de estos mismos prelados.

Pérez Roy, tras ser llamado a la Corte, recaló en la diócesis de Guadix-Baza (Granada), como también acabaron haciéndolo José Lainez y Diego Serrano, aunque este tras haber ocupado durante largos años la silla episcopal de Segorbe. La cátedra accitana, en la que los tres confluyeron en la culminación de su carrera eclesiástica, suponía toda una declaración de intenciones. $Y$ es que, mientras que el mercedario Serrano se retiraba allí a morir - pues duró su pontificado escasas dos semanas- para quienes habían sido obispo de Elna y electo de Solsona, suponía una retirada de la primera línea política y una vuelta a su fin primigenio como pastores de almas, en medio de una diócesis de discretas rentas, con relativa tranquilidad social y en la que seguía existiendo el imperativo de asentar las bases del ordenamiento cristiano.

\section{FUENTES}

[s.a.] 1640. Carta que ha enviada la vila de Perpinyà a Cathalunya, ahont va contant totas sas desdichas. Barcelona: Estampa de Jaume Romeu.

[s.a.] 1642. Dialogo verdader, gracios y apacible dels felices y bons successos de la guerra de Cathalunya. Barcelona: Gabriel Nogués.

Diputación del General 1640. Iustificacio en conciencia de aver pres lo Principat de Catalunya las armas. Barcelona: Gabriel Nogués.

Gracián, Baltasar. 1657. El Criticón. V. 3. Madrid: Pablo del Val.

Lainez, José. 1641. El privado christiano de loseph y Daniel que fueron balanzas de los validos. Madrid: Imprenta del Reyno.

\footnotetext{
66 Lainez 1650, 14-15.
}

$\begin{array}{ll}67 & \text { Busquets } 1987 . \\ 68 & \text { Idem }\end{array}$ 
Lainez, José. 1642. Daniel cortesano en Babilonia. Madrid: Juan Sánchez.

Lainez, José. 1650. Acción de gracias a Dios Nuestro Señor por la entrada triunfal la ciudad de Lérida. Pamplona.

Peña, Narciso. 1709. Anales de Cataluña. Barcelona: Juan Pablo Martí.

Ros, Alexandre. 1646. Cataluña desengañada, discursos políticos. Nápoles: Egido Longo.

Sala, Gaspar. 1640. Proclamación catholica a la Magestad piadosa de Felipe el Grande. Lisboa: Antonio Álvarez.

Sala, Gaspar. 1642. Lágrimas catalanas al entierro y obsequias del Ilustre Deputado Ecclesiástico de Cataluña Pau Claris. Barcelona: Gabriel Nogués.

Salmerón, Marcos. 1646. Recuerdos históricos y políticos de los seruicios que los Generales... Valencia: Chrysostomo Garriz.

Suárez, Pedro. 1696. Historia del Obispado de Guadix y Baza. Madrid: Antonio Román.

Valladares, Antonio. 1790. Semanario erudito. Madrid: Antonio Espinosa.

\section{BIBLIOGRAFÍA}

Arredondo, María Soledad. 1998. «Armas de papel. Quevedo y sus contemporáneos ante la Guerra de Cataluña». La Perinola 2: 117-151.

Batllori, Miguel. 1958. "Gracián entre la Corte y Cataluña en armas (1640-1646)». Revista de estudios políticos 100: 167-194.

Burgos, Francisco Javier y Manuel Peña. 1984. «Aportaciones sobre e enfrentamiento ideológico entre Castilla y Cataluña en el siglo XVII. La publicística catalana». En Primer Congrés d'Història Moderna de Catalunya, 557-568. Barcelona: Universidad de Barcelona.

Busquets, Joan. 1987. «Bisbes espanyols i bisbes francesos a la Guerra dels Segadors». El Barroc català. Disponible en: http://hdl.handle. net/10256.1/685

Cánovas del Castillo, Antonio. 1888. Estudios del reinado de Felipe IV. Madrid: Imprenta de Antonio Pérez Dubrull.

Costa, Domingo. 1959. Memorias de la ciudad de Solsona y su iglesia. Barcelona: Balmes.

Domínguez Ortiz, Antonio. 1960. Política y hacienda de Felipe IV. Madrid: Derecho Financiero.
Domínguez Ortiz, Antonio. 1970. La sociedad española en el siglo XVII. V. 2. Madrid: CSIC.

Elliot, John H. 1976. La rebelión de los catalanes, 1598-1640. Madrid: Siglo XXI.

Ettinghausen, Henry. 1993. La Guerra dels Segadors a través de la premsa de l'época. Barcelona: Curial.

Garí, José Antonio. 1875. Biblioteca Mercedaria. Barcelona: Impr. Viuda de Plà.

Madurell, Josep Maria. 1948. «El concilio tarraconense de 1640». Analecta sacra Tarraconensia 21: 121-137.

Nadal, Joaquim. 1979. Dos segles d'obscuritat (XVI i XVII). Barcelona: Dopesa.

Riera, Enric. 1986. "Prolegòmens de la Guerra dels Segadors a les comarques gironines. Els fets de Montiró». Annals de l'Institut d'Estudis Empordanesos 19: 115-142.

Sanabre, José. 1968. Parlaments de Pau Claris i de Pau Duran a I'Assemblea del Tres Braços. 11 de setembre de 1640. Barcelona: Edigraf.

Sanabre, José. 1985. La resistència del Rosselló a incorporar-se a França. Perpiñán: Llibres del Trabucaire.

Sanz, Porfirio. 2004. "El peso de la milicia. "Alojamiento foral" y conflicto de jurisdicciones en la frontera catalano-aragonesa durante la guerra de Cataluña (1640-1652)». Revista de Historia Moderna 22: 173-208. https://doi.org/10.14198/RHM2004.22.06

Simon, Antoni. 1999. «Ideologia i identidad nacional a la Revolució Catalana de 1640». Cercles: revista d'història cultural 2: 10-23.

Torres, Xavier. 2012a. "Contra la décima eclesiástica: en los albores de la revuelta catalana de 1640 ». En Actas de la XI Reunión Científica de la Fundación Española de Historia Moderna, ed. Antonio Jiménez y Julian Lozano, 885-896. Granada: Universidad de Granada.

Torres, Xavier. 2012b. «Església i ciutat: la revolta contra la dècima (1634)». Annals de I'Insttut d'Estudis Gironins 53: 31-47.

Torres, Xavier. 2014. "La guerra de separación de Cataluña en la monarquía hispánica de los Austrias (1640-1659)». En Los bombarderos de Barcelona, coord. Juan Pérez, 33-64. Madrid: Los Libros de la Catarata.

Torres, Xavier. 2015. «Frailes y campesinos en la guerra de separación de Cataluña (1640-1660)». Hispania 249: 69-94. https://doi. org/10.3989/hispania.2015.003 